\title{
KETERPADUAN PASAR IKAN LAUT SEGAR DI PASAR MUARA BARU JAKARTA UTARA DAN PASAR JEMBATAN LIMA JAKARTA BARAT \\ Dwi Anggara, Mercy Patanda
}

Fakultas Perikanan dan Ilmu Kelautan

Universitas Satya Negara Indonesia , Jakarta

\begin{abstract}
ABSTRAK
Penelitian ini bertujuan untuk 1) Menganalisis Tingkat Keterpaduan Pasar Ikan Laut Segar di Muara Baru Jakarta Utara dan Pasar Jembatan Lima Jakarta Barat. 2) Mengetahui kondisi pasar ikan di Muara Baru Jakarta Utara dan Pasar Jembatan Lima Jakarta Barat. Penelitian ini dilaksanakan dari bulan Mei sampai Juli 2018 di Pelelangan Pasar Ikan Muara Baru, Jakarta Utara. Metode penelitian yang digunakan yaitu dengan mengumpulkan data primer dan data sekunder dengan metode rumus analisis Index of Market Connection.

Hasil dari perhitungan Index of Market Connection didapatkan hasil nilai IMC pada Ikan Bandeng sebesar 0,946. Nilai IMC pada Ikan Kembung sebesar 0,152. Nilai IMC pada Ikan Tenggiri sebesar -0,022. Dan Nilai pada Ikan Tongkol sebesar 2,028 .

Kesimpulan dari penelitian ini adalah Berdasarkan Index Of Market Connection dari keempat ikan Bandeng, Kembung, Tenggiri, Tongkol didapatkan bahwa terdapat keterpaduan pasar jangka pendek dan jangka panjang di tiga ikan yaitu Bandeng,Kembung,dan Tenggiri. Sedangkan untuk ikan Tongkol hanya terdapat keterpaduan jangka pendek dan tidak terdapat keterpaduan jangka panjang. Kondisi pasar ikan di muara baru dan jembatan lima cukup strategis dan para pelapak ikan pun tertata dengan rapih sehingga terciptanya kenyamanan saat proses transaksi jual beli antar pedagang dengan konsumen.
\end{abstract}

Kata Kunci: IMC (Index Of Market Connection), Keterpaduan Pasar, Jangka Pendek, Jangka Panjang. 


\section{PENDAHULUAN}

Salah satu potensi sumberdaya kelautan dan perikanan yang telah memberikan kontribusi cukup signifikan bagi perekonomian nasional adalah sub sector perikanan tangkap. Hasil produksi perikanan di Indonesia sebagian besar berasal dari usaha penangkapan ikan di laut, sementara produksi perikanan budidaya masih relative kecil.

Pemasaran merupakan hal yang paling penting dalam menjalankan sebuah usaha perikanan karena pemasaran merupakan tindakan ekonomi yang berpengaruh terhadap tinggi rendahnya pendapatan nelayan. Pemasaran produk perikanan dan kelautan dalam negeri maupun ekspor, sebagian besar masih ditentukan oleh pembeli/konsumen (buyer market). Kondisi ini menyebabkan harga jual produk perikanan pada umumnya kurang menguntungkan nelayan selaku produsen.

Integrasi pasar atau Keterpaduan pasar merupakan salah satu indikator dari efisiensi pemasaran, khususnya efiesiensi harga. Keterpaduan pasar merupakan penggabungan antara beberapa lembaga pemasaran yang secara fungsional dan ekonomi menjadi satu kesatuan dalam system pemasaran. Asmarantaka (2009) menyatakan bahwa integrasi pasar merupakan suatu ukuran yang menujukkan seberapa jauh perubahan harga yang terjadi di pasar acuan sehingga menyebabkan terjadinya perubahan harga pada pasar pengikutnya.

Latar Belakang fenomena permasalahan penelitian ini yaitu adanya perbedaan harga ikan di pasar Muara Baru Jakarta Utara dan Pasar Jembatan Lima Jakarta Barat. Hal tersebut dapat dilihat pada Tabel 1. dan Tabel 2. perubahan harga ikan di Pasar Muara Baru Jakarta Utara dan Pasar Jembatan Lima Jakarta Barat dibawah ini.

Tabel 1. Harga Rata Rata Ikan Bandeng di Pasar Muara Baru Jakarta Utara

\begin{tabular}{|l|ll|ll|ll|ll|}
\hline bulan & $\begin{array}{l}\text { Harga } \\
\text { minggu } \\
(\mathrm{Rp} / \mathrm{kg})\end{array}$ & ke-1 & $\begin{array}{l}\text { Harga } \\
\text { minggu } \\
(\mathrm{Rp} / \mathrm{kg})\end{array}$ & $\begin{array}{l}\text { ke-2 } \\
\text { karga }\end{array}$ & $\begin{array}{l}\text { ikan } \\
\text { minggu } \\
(\mathrm{Rp} / \mathrm{kg})\end{array}$ & $\begin{array}{l}\text { Harga } \\
\text { minggu } \\
(\mathrm{Rp} / \mathrm{kg})\end{array}$ & ke-4 \\
\hline Januari & 25000 & 26000 & 27000 & 28000 \\
\hline
\end{tabular}




\begin{tabular}{|l|l|l|l|l|}
\hline Februari & 30000 & 31000 & 32000 & 33000 \\
\hline Maret & 31000 & 30000 & 31000 & 32000 \\
\hline April & 32000 & 33000 & 30000 & 35000 \\
\hline Mei & 30000 & 32000 & 31000 & 30000 \\
\hline Juni & 30000 & 31000 & 29000 & 31000 \\
\hline Juli & 32000 & 33000 & 34000 & 35000 \\
\hline Agustus & 29000 & 30000 & 33000 & 35000 \\
\hline September & 33000 & 32000 & 31000 & 30000 \\
\hline Oktober & 35000 & 33000 & 30000 & 28000 \\
\hline November & 29000 & 31000 & 32000 & 30000 \\
\hline Desember & 29000 & 30000 & 31000 & 32000 \\
\hline
\end{tabular}

Sumber : Unit Pelaksana Teknis Pelabuhan Perikanan Samudera Nizam Zachman Jakarta (Data Harga Ikan di Pasar Muara Baru Tahun 2017)

Tabel 2. Harga Rata Rata Ikan Bandeng di Pasar Jembatan Lima Jakarta Barat

\begin{tabular}{|c|c|c|c|c|}
\hline bulan & $\begin{array}{ll}\text { Harga } & \text { ikan } \\
\text { minggu } & \text { ke-1 } \\
(\mathrm{Rp} / \mathrm{kg}) & \end{array}$ & $\begin{array}{ll}\text { Harga } & \text { ikan } \\
\text { minggu } & \text { ke-2 } \\
(\mathrm{Rp} / \mathrm{kg}) & \\
\end{array}$ & $\begin{array}{ll}\text { Harga } & \text { ikan } \\
\text { minggu } & \text { ke-3 } \\
(\mathrm{Rp} / \mathrm{kg}) & \\
\end{array}$ & $\begin{array}{ll}\text { Harga } & \text { ikan } \\
\text { minggu } & \text { ke-4 } \\
(\mathrm{Rp} / \mathrm{kg}) & \\
\end{array}$ \\
\hline Januari & 26000 & 27000 & 29000 & 30000 \\
\hline Februari & 31000 & 32000 & 32000 & 33000 \\
\hline Maret & 31000 & 30000 & 31000 & 32000 \\
\hline April & 32000 & 33000 & 30000 & 35000 \\
\hline Mei & 35000 & 32000 & 31000 & 30000 \\
\hline Juni & 30000 & 31000 & 29000 & 31000 \\
\hline Juli & 32000 & 33000 & 34000 & 35000 \\
\hline Agustus & 30000 & 31000 & 35000 & 33000 \\
\hline September & 33000 & 32000 & 31000 & 30000 \\
\hline Oktober & 35000 & 33000 & 30000 & 28000 \\
\hline November & 29000 & 31000 & 32000 & 30000 \\
\hline Desember & 30000 & 31000 & 31000 & 32000 \\
\hline
\end{tabular}

Sumber : Pejabat Pengelola Informasi dan Dokumentasi Pasar Jaya DKI Jakarta (Data

Harga Ikan di Pasar Jembatan Lima 2017)

\section{METODOLOGI}

Penelitian dilaksanakan dari bulan Mei sampai Juli 2018 di Pelelangan Pasar Ikan Muara Baru, Jakarta Utara. Metode yang digunakan dalam penelitian ini adalah metode observasi. Metode observasi pengamatan secara langsung ke objek penelitian untuk melihat dari dekat kegiatan yang dilakukan. 
Analisis data dilakukan secara deskriptif dan kuantitatif. Alat analisis yang digunakan adalah Index Of Market Connection. Untuk mengetahui tingkat (keterpaduan) antara pasar ikan Muara Baru dengan pasar Jembatan Lima dianalisa secara statistik dengan menggunakan model Autoregresive Distributed Lag. Model ekonometrika tersebut diduga dengan menggunakan Metode Kuadrat Terkecil (Ordinary Least Square). Lebih lanjut model fungsionalnya dapat ditulis sebagai berikut :

\section{HJt = b1(HJt-1) + b2(HAt- HAt-1 $)+$ b3(HAt-1 $)+$ et}

dimana :

HJt = Harga ikan dua mingguan di pasar Muara Baru

HJt-1 = Selisih harga ikan dua mingguan di pasar Muara Baru

HAt = Harga ikan dua mingguan di pasar Jembatan Lima

HAt-1 = Selisih harga ikan dua mingguan di pasar Jembatan Lima

bi $=$ Parameter estimasi

et $=$ Error model

dengan Index of Market Connection (IMC) sebagai berikut :

\section{$\mathrm{IMC}=\mathrm{b} 1 / \mathrm{b3}$}

Keterangan :

IMC = Salah satu metode yang digunakan untuk mengukur keterpaduan digunakan untuk mengukur keterpaduan mengukur bagaimana harga di pasar sentral (Muara Baru) dipengaruhi oleh harga di pasar tujuan (Jembatan Lima) dengan mempertimbangkan harga pada waktu yang lalu dengan harga pada saat ini.

Model integrasi ini dapat menguji dua aspek dari integrasi pasar. Aspek pertama adalah aspek integrasi jangka panjang antara pasar sentral (Muara Baru)dan pasar tujuan (Jembatan Lima). Aspek kedua adalah aspek perubahan jangka pendek, yaitu bagaimana perubahan harga jangka pendek dari marjin yang terjadi di antara pasar sentral (Muara Baru) dan pasar tujuan (Jembatan Lima).

B $(1,2,3)=$ Nilai koefisien regresi

Dimana: 
Jika IMC $<1$ maka terdapat derajat integrasi pasar jangka panjang yang relatif tinggi antara pasar sentral (Muara Baru) dan pasar tujuan (Jembatan Lima). IMC =0, artinya perubahan harga pasar sentral (Muara Baru) tidak berpengaruh terhadap perubahan harga di tingkat pasar tujuan (Jembatan Lima). IMC > 1 dan nyata, maka antara pasar sentral (Muara Baru) dengan pasar tujuan (Jembatan Lima) tidak terintegrasi, hal ini berarti harga di pasar sentral (Muara Baru) dengan pasar tujuan (Jembatan Lima) tidak saling mempengaruhi.

Integrasi pasar jangka panjang disebut juga keterkaitan pasar dalam menjelaskan bagaimana para pelaku pemasaran berhasil menghubungkan pasar yang secara geografi terpisah melalui informasi dan komoditas. Sedangkan integrasi jangka pendek bisa dilihat dari nilai b2, semakin mendekati satu pada nilai b2, maka derajat asosiasinya semakin tinggi.

\section{PEMBAHASAN}

\section{Kondisi Pasar Muara Baru Jakarta Utara}

Pasar Muara Baru Jakarta Utara melakukan kegiatan lelang secara rutin setiap hari mulai pukul 16.00 WIB sampai dengan pukul 02.00 WIB. Lokasi pasar ikan Muara Baru ini cukup strategis karena letaknya berada di dalam Pelabuhan Perikanan Samudera Nizam Zachman Jakarta. Pasar ikan Muara Baru Jakarta Utara dibagi kedalam beberapa blok yang dimana ditiap blok terdapat nomor yang berbeda beda di setiap lapak pedagang ikan, hal tersebut dilakukan agar para pedagang ikan dapat tertata dengan rapih sehingga para pengunjung akan nyaman saat melakukan proses transaksi jual beli ikan di pasar ikan muara baru.

Transaksi yang dilakukan di pasar ini umumnya menggunakan transaksi tunai adapun transaksi non tunai jarang dilakukan karena para pedagang di pasar ini lebih senang jika transaksi dilakukan secara tunai agar hasil uangnya bisa langsung dipergunakan untuk mencukupi kebutuhan sehari hari.

\section{Kondisi Pasar Jembatan Lima Jakarta Barat}


Pasar Jembatan Lima Jakarta Barat melakukan kegiatan jual beli secara rutin setiap hari mulai pukul 00.00 WIB sampai dengan pukul 07.00 WIB. Lokasi pasar jembatan lima ini cukup strategis karena akses menuju ke lokasi pasar cukup mudah untuk dikunjungi. Ikan yang ada dipasar jembatan lima ini umumnya berasal dari pelabuhan muara baru jakarta utara. Transaksi yang dilakukan di pasar ini juga umumnya menggunakan transaksi tunai adapun transaksi non tunai jarang dilakukan karena para pedagang di pasar ini lebih senang jika transaksi dilakukan secara tunai agar hasil uangnya bisa langsung dipergunakan untuk mencukupi kebutuhan sehari hari.

Analisis Keterpaduan Pasar Ikan Bandeng (Chanos chanos) Hasil perhitungan SPSS

b. Predictors: (Constant), HAt1, HAtHAt1, HJt1

\begin{tabular}{|c|c|c|c|c|c|c|c|c|}
\hline \multirow{2}{*}{\multicolumn{2}{|c|}{ Model }} & \multicolumn{2}{|c|}{ Unstandardized Coefficients } & \multirow{2}{*}{$\begin{array}{c}\begin{array}{c}\text { Standardized } \\
\text { Coefficients }\end{array} \\
\text { Beta } \\
\end{array}$} & \multirow[b]{2}{*}{$t$} & \multirow[b]{2}{*}{ Sig. } & \multicolumn{2}{|c|}{$95,0 \%$ Confidence Interval for B } \\
\hline & & $\mathrm{B}$ & Std. Error & & & & Lower Bound & Upper Bound \\
\hline \multirow[t]{4}{*}{1} & (Constant) & 655,012 & 1105,520 & &, 592 &, 557 & $-1573,017$ & 2883,041 \\
\hline & HJt1 &, 476 &, 141 & 1,077 & 3,376 & .002 &, 192 &, 759 \\
\hline & HAtHAt1 & .946 & .040 & 1,829 & 23,410 &, 000 & .864 & 1,027 \\
\hline & HAt1 &, 503 & 151 & 1,121 & 3,319 &, 002 &, 197 &, 808 \\
\hline
\end{tabular}

a. Dependent Variable: HJt

\begin{tabular}{|c|c|c|c|c|c|}
\hline \multicolumn{6}{|c|}{ Coefficient Correlations $^{a}$} \\
\hline & & & HAt1 & HAtHAt1 & HJt1 \\
\hline \multirow[t]{6}{*}{1} & Correlations & HAt1 & 1,000 &, 364 &,- 974 \\
\hline & & HAtHAt1 &, 364 & 1,000 &,- 165 \\
\hline & & HJt1 &,- 974 & -165 & 1,000 \\
\hline & Covariances & HAt1 &, 023 &, 002 &,- 021 \\
\hline & & HAtHAt1 &, 002 &, 002 &,- 001 \\
\hline & & $\mathrm{HJt1}$ &,- 021 &,- 001 &, 020 \\
\hline
\end{tabular}

Casewise Diagnostics ${ }^{\text {a }}$
\begin{tabular}{|l|r|l|l|l|}
\hline Case Number & Std. Residual & HJt & $\begin{array}{c}\text { Predicted } \\
\text { Value }\end{array}$ & Residual \\
\hline 3 & 4,619 & 27000 & 24695,64 & 2304,357 \\
\hline
\end{tabular}

Dari hasil perhitungan SPSS di dapatkan nilai Metode Kuadrat Terkecil (Ordinary Least Square) yaitu ;

$\mathrm{HJt}=\mathrm{b} 1(\mathrm{HJt}-1)+\mathrm{b} 2(\mathrm{HAt}-\mathrm{HAt}-1)+\mathrm{b} 3(\mathrm{HAt}-1)+\mathrm{et}$

$\mathrm{Y}=0,476($ HJt-1) + 0,946 (HAt-HAt-1) + 0,503 (HAt-1) 
Keterpaduan pasar dalam jangka panjang antara harga ikan bandeng di Muara Baru dan Jembatan Lima dapat diketahui dengan nilai Index of Market Connection (IMC) yang diperoleh nilai IMC sebagai berikut;

$\mathrm{IMC}=\mathrm{b} 1 / \mathrm{b} 3$

$=0,476 / 0,503$

$=0,946$

Nilai IMC yang diperoleh sebesar 0.946 (IMC<1) mengindikasikan adanya integrasi/keterpaduan jangka panjang yang relatif tinggi antara harga ikan bandeng di Muara Baru dan Jembatan Lima. Dengan kata lain, pasar ikan bandeng di Muara Baru dan jembatan Lima semakin terintegrasi dalam jangka panjang sehingga saat harga di Muara Baru naik maka harga di Jembatan Lima juga naik.

Dua pasar dikatakan terpadu secara sempurna dalam jangka pendek apabila nilai koefisien korelasinya sama dengan satu. Keterpaduan pasar jangka pendek menunjukan bagaimana perubahan harga dalam jangka pendek di pasar Muara Baru dipengaruhi oleh perubahan jangka pendek yang terjadi diantara pasar Muara Baru dengan Pasar Jembatan Lima, diwakili oleh nilai koefisien b2. Koefisien peubah b2 harga ikan bandeng di pasar tujuan (Jembatan Lima) antara bulan sebelumnya dengan bulan sekarang di pasar Muara Baru adalah 0,946 sehingga kedua pasar terpadu dalam jangka pendek.

Persamaan tersebut juga menunjukkan nilai koefisien harga ikan bandeng di Muara Baru pada waktu t-1 (b1) sebesar 0,476, dan koefisien harga ikan bandeng di Jembatan Lima pada waktu t-1 (b3) sebesar 0,503 serta koefisien harga ikan bandeng di Jembatan Lima pada waktu t dan t-1 (b2) sebesar 0.946.

Analisis Keterpaduan Pasar Ikan Kembung (Rastrelliger) Hasil Perhitungan SPSS 


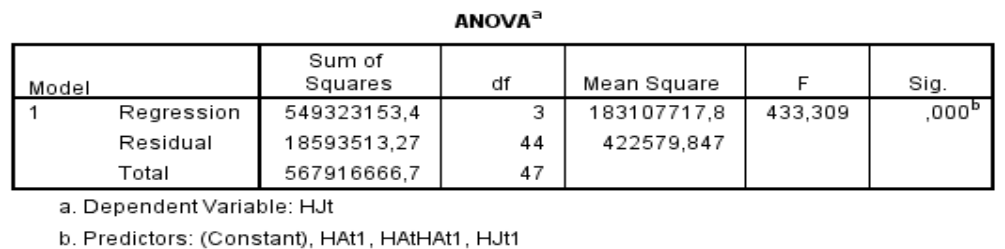

b. Predictors: (Constant), HAt1, HAtHAt1, HJt1

\begin{tabular}{|c|c|c|c|c|c|c|c|c|}
\hline \multicolumn{9}{|c|}{ Coefficients $^{a}$} \\
\hline & & \multicolumn{2}{|c|}{ Unstandardized Coefficients } & $\begin{array}{c}\text { Standardized } \\
\text { Coefficients }\end{array}$ & \multirow[b]{2}{*}{$t$} & \multirow[b]{2}{*}{ Sig. } & \multicolumn{2}{|c|}{$95,0 \%$ Confidence Interval for B } \\
\hline \multicolumn{2}{|c|}{ Model } & $\mathrm{B}$ & Std. Error & Beta & & & Lower Bound & Upper Bound \\
\hline 1 & (Constant) & $-2532,224$ & 994,960 & & $-2,545$ & ,015 & $-4537,434$ & $-527,013$ \\
\hline & HJt1 & 138 & 138 &, 225 & 998 & ,324 &,- 141 & 417 \\
\hline & HAtHAt1 & 1,000 & 030 & 1,644 & 33,585 &, 000 & 940 & 1,060 \\
\hline & HAt1 & ,903 & 138 & 1,498 & 6,527 &, 000 & 624 & 1,182 \\
\hline
\end{tabular}

a. Dependent Variable: $\mathrm{HJt}$

\begin{tabular}{|c|c|c|c|c|c|}
\hline \multicolumn{6}{|c|}{ Coefficient Correlations $^{a}$} \\
\hline & & & HAt1 & HAtHAt1 & HJt1 \\
\hline \multirow[t]{6}{*}{1} & \multirow[t]{3}{*}{ Correlations } & HAt1 & 1,000 & , 183 &,- 977 \\
\hline & & HAtHAt1 & 183 & 1,000 &,- 006 \\
\hline & & HJt1 &,- 977 &,- 006 & 1,000 \\
\hline & \multirow[t]{3}{*}{ Covariances } & HAt1 & 019 & .001 &,- 019 \\
\hline & & HAtHAt1 & ,001 & 001 & $-2,285 E-005$ \\
\hline & & HJt1 &,- 019 & $-2,285 E-005$ &, 019 \\
\hline
\end{tabular}

a. Dependent Variable: $\mathrm{HJt}$

Dari hasil perhitungan SPSS di dapatkan nilai Metode Kuadrat Terkecil (Ordinary Least Square) yaitu ;

$$
\begin{aligned}
& \text { HJt }=\text { b1 (HJt-1) + b2(HAt- HAt-1) + b3(HAt-1) + et } \\
& \mathrm{Y}=0,138(\text { HJt-1) + 1,000 (HAt-HAt-1) + 0,903 (HAt-1) }
\end{aligned}
$$

Keterpaduan pasar dalam jangka panjang antara harga ikan kembung di Muara Baru dan Jembatan Lima dapat diketahui dengan nilai Index of Market Connection (IMC) yang diperoleh nilai IMC sebagai berikut;

$$
\begin{aligned}
& \text { IMC = b1/b3 } \\
& =0,138 / 0,903 \\
& =0,152
\end{aligned}
$$

Nilai IMC yang diperoleh sebesar 0.152 (IMC<1) mengindikasikan adanya integrasi/keterpaduan jangka panjang yang relatif tinggi antara harga ikan kembung di Muara Baru dan Jembatan Lima. Dengan kata lain, pasar ikan kembung di Muara Baru dan Jembatan Lima semakin terintegrasi dalam jangka panjang sehingga saat harga di Muara Baru naik maka harga di Jembatan Lima juga naik.

Dua pasar dikatakan terpadu secara sempurna dalam jangka pendek apabila nilai koefisien korelasinya sama dengan satu. Keterpaduan pasar jangka pendek 
menunjukan bagaimana perubahan harga dalam jangka pendek di pasar Muara Baru dipengaruhi oleh perubahan jangka pendek yang terjadi diantara pasar Muara Baru dengan Pasar Jembatan Lima, diwakili oleh nilai koefisien b2. Koefisien peubah b2 harga ikan kembung di pasar tujuan (Jembatan Lima) antara bulan sebelumnya dengan bulan sekarang di pasar Muara Baru adalah 1,000 sehingga kedua pasar terpadu dalam jangka pendek.

Persamaan tersebut juga menunjukkan nilai koefisien harga ikan kembung di Muara Baru pada waktu t-1 (b1) sebesar 0,138, dan koefisien harga ikan kembung di Jembatan Lima pada waktu t-1 (b3) sebesar 0,903 serta koefisien harga ikan kembung di Jembatan Lima pada waktu t dan t-1 (b2) sebesar 1,000.

\section{Analisis Keterpaduan Pasar Ikan Tenggiri (Scomberomorini)}

\section{Hasil Perhitungan SPSS}

\begin{tabular}{|c|c|c|c|c|c|c|c|c|}
\hline \multicolumn{9}{|c|}{ Coefficients $^{a}$} \\
\hline \multirow[b]{2}{*}{ Model } & & \multicolumn{2}{|c|}{ Unstandardized Coefficients } & \multirow{2}{*}{$\begin{array}{c}\text { Standardized } \\
\text { Coefficients } \\
\text { Beta }\end{array}$} & \multirow[b]{2}{*}{$\mathrm{t}$} & \multirow[b]{2}{*}{ Sig. } & \multicolumn{2}{|c|}{$95,0 \%$ Confidence Interval for $B$} \\
\hline & & B & Std. Error & & & & Lower Bound & Upper Bound \\
\hline 1 & (Constant) & $-472,998$ & 1323,160 & & -.357 & .722 & $-3139,652$ & 2193,656 \\
\hline & Hut1 & -.022 & .151 & -.067 & -.145 & 886 & -.325 & .282 \\
\hline & Hathat1 & .974 & 021 & 3,038 & 46,785 & 000 &, 933 & 1,016 \\
\hline & Hat1 & .996 & .147 & 3,153 & 6,762 & 000 & .699 & 1,293 \\
\hline
\end{tabular}

a. Dependent Variable: Hut

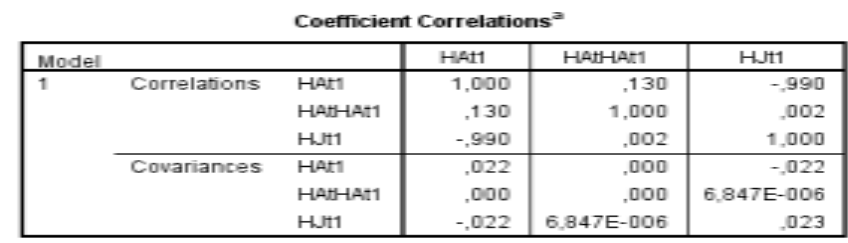

a. Dependent Variable: $H^{2}$

\begin{tabular}{l} 
Casewise Diagnostics \\
\begin{tabular}{|l|r|l|l|l|}
\hline Case Number & Std. Residual & Hut & $\begin{array}{c}\text { Predicted } \\
\text { Value }\end{array}$ & Residual \\
\hline 10 & $-4,257$ & 63000 & 64872,87 & $-1872,871$ \\
27 & $-4,256$ & 63000 & 64872,22 & $-1872,219$ \\
\hline
\end{tabular} \\
\hline
\end{tabular}

Dari hasil perhitungan SPSS di dapatkan nilai Metode Kuadrat Terkecil (Ordinary Least Square) yaitu ;

HJt $=\mathrm{b} 1($ HJt-1 $)+\mathrm{b} 2($ HAt - HAt-1 $)+b 3($ HAt-1 $)+$ et

$\mathrm{Y}=-0,022($ HJt-1) + 0,974 (HAt-HAt-1) + 0,996 (HAt-1)

Keterpaduan pasar dalam jangka panjang antara harga ikan tenggiri di Muara Baru dan Jembatan Lima dapat diketahui dengan nilai Index of Market Connection (IMC) yang diperoleh nilai IMC sebagai berikut; 
$\mathrm{IMC}=\mathrm{b} 1 / \mathrm{b} 3$

$=-0,022 / 0,996$

$=-0,022$

Nilai IMC yang diperoleh sebesar -0.022 (IMC<1) mengindikasikan adanya integrasi/keterpaduan jangka panjang yang relatif tinggi antara harga ikan tenggiri di Muara Baru dan Jembatan Lima. Dengan kata lain, pasar ikan tenggiri di Muara Baru dan Jembatan Lima semakin terintegrasi dalam jangka panjang sehingga saat harga di Muara Baru naik maka harga di Jembatan Lima juga naik.

Dua pasar dikatakan terpadu secara sempurna dalam jangka pendek apabila nilai koefisien korelasinya sama dengan satu. Keterpaduan pasar jangka pendek menunjukan bagaimana perubahan harga dalam jangka pendek di pasar Muara Baru dipengaruhi oleh perubahan jangka pendek yang terjadi diantara pasar Muara Baru dengan Pasar Jembatan Lima, diwakili oleh nilai koefisien b2. Koefisien peubah b2 harga ikan tenggiri di pasar tujuan (Jembatan Lima) antara bulan sebelumnya dengan bulan sekarang di pasar Muara Baru adalah 0,974 sehingga kedua pasar terpadu dalam jangka pendek.

Persamaan tersebut juga menunjukkan nilai koefisien harga ikan tenggiri di Muara Baru pada waktu t-1 (b1) sebesar -0,022, dan koefisien harga ikan tenggiri di Jembatan Lima pada waktu t-1 (b3) sebesar 0,996 serta koefisien harga ikan tenggiri di Jembatan Lima pada waktu t dan t-1 (b2) sebesar 0.974.

\section{Analisis Keterpaduan Pasar Ikan Tongkol (Euthynnus affinis) Hasil Perhitungan SPSS}




\begin{tabular}{|c|c|c|c|c|c|c|c|c|}
\hline \multicolumn{9}{|c|}{ Coefficients $^{\circ}$} \\
\hline \multirow[b]{2}{*}{ Model } & & \multicolumn{2}{|c|}{ Unstandardized Coefficients } & \multirow{2}{*}{$\begin{array}{c}\text { Standardized } \\
\text { Coefficients }\end{array}$} & \multirow[b]{2}{*}{$\mathrm{t}$} & \multirow[b]{2}{*}{ Sig. } & \multicolumn{2}{|c|}{$95,0 \%$ Confidence Interval for $B$} \\
\hline & & $\mathrm{B}$ & Std. Error & & & & Lower Bound & Upper Bound \\
\hline 1 & (Constant) & 504,962 & 668,312 & & .756 & .454 & $-841,933$ & 1851,857 \\
\hline & HJt1 & .645 & 115 & 1.280 & 5,620 & ,000 & .414 & .877 \\
\hline & HAtHAt1 & .923 & .024 & 1,753 & 39,127 & ,000 & 875 & .971 \\
\hline & HAt1 & 318 & , 106 & 674 & 3,012 & ,004 & 105 & 531 \\
\hline
\end{tabular}

a. Dependent Variable: HJt

\begin{tabular}{|c|c|c|c|c|c|}
\hline \multicolumn{6}{|c|}{ Coefficient Correlations ${ }^{a}$} \\
\hline & & & HAt1 & Hatthat1 & Hut1 \\
\hline \multirow[t]{6}{*}{1} & Correlations & Hat1 & 1,000 &,- 014 &,- 980 \\
\hline & & HANHATI &,- 014 & 1,000 & 184 \\
\hline & & Hut1 & -980 & .184 & 1,000 \\
\hline & Corariances & Hat1 & 011 & $-3,532 E-005$ &,- 012 \\
\hline & & HAIHATI & $-3,532 \mathrm{E}-005$ & 001 & .000 \\
\hline & & Hut1 &,- 012 & 000 & 013 \\
\hline
\end{tabular}

a. Dependent Variable: HJt

\begin{tabular}{|c|c|c|c|c|}
\hline \multicolumn{5}{|c|}{ Casewise Diagnostics $^{a}$} \\
\hline Case Number & Std. Residual & Hut & $\begin{array}{c}\text { Predicted } \\
\text { Value }\end{array}$ & Residual \\
\hline 15 & 4,728 & 28000 & 26181,95 & 1818,051 \\
\hline 19 & $-3,228$ & 29000 & 30241,25 & $-1241,250$ \\
\hline
\end{tabular}

Dari hasil perhitungan SPSS di dapatkan nilai Metode Kuadrat Terkecil (Ordinary Least Square) yaitu ;

HJt $=\mathrm{b} 1($ HJt-1) $+\mathrm{b} 2($ HAt - HAt- 1$)+\mathrm{b} 3($ HAt- 1$)+$ et

$\mathrm{Y}=0,645($ HJt-1) + 0,923 (HAt-HAt-1) + 0,318 (HAt-1)

Keterpaduan pasar dalam jangka panjang antara harga ikan tongkol di Muara Baru dan Jembatan Lima dapat diketahui dengan nilai Index of Market Connection (IMC) yang diperoleh nilai IMC sebagai berikut;

$\mathrm{IMC}=\mathrm{b} 1 / \mathrm{b} 3$

$=0,645 / 0,318$

$=2,028$

Nilai IMC yang diperoleh sebesar 2,028 (IMC>1) mengindikasikan tidak adanya integrasi/keterpaduan jangka panjang karena harga ikan tongkol di Muara Baru dan Jembatan Lima tidak saling mempengaruhi. Dengan kata lain, pasar ikan tongkol di Muara Baru dan Jembatan Lima tidak terintegrasi dalam jangka panjang sehingga saat harga di Muara Baru naik maka harga di Jembatan lima belum tentu juga naik.

Dua pasar dikatakan terpadu secara sempurna dalam jangka pendek apabila nilai koefisien korelasinya sama dengan satu. Keterpaduan pasar jangka pendek 
menunjukan bagaimana perubahan harga dalam jangka pendek di pasar Muara Baru dipengaruhi oleh perubahan jangka pendek yang terjadi diantara pasar Muara Baru dengan Pasar Jembatan Lima, diwakili oleh nilai koefisien b2. Koefisien peubah b2 harga ikan tongkol di pasar tujuan (Jembatan Lima) antara bulan sebelumnya dengan bulan sekarang di pasar Muara Baru adalah 0,923 sehingga kedua pasar terpadu dalam jangka pendek.

Persamaan tersebut juga menunjukkan nilai koefisien harga ikan tongkol di Muara Baru pada waktu t-1 (b1) sebesar 0,645, dan koefisien harga ikan tongkol di Jembatan Lima pada waktu t-1 (b3) sebesar 0,318 serta koefisien harga ikan tongkol di Jembatan Lima pada waktu t dan t-1 (b2) sebesar 0.923.

\section{KESIMPULAN DAN SARAN}

\section{Kesimpulan}

Berdasarkan penelitian Keterpaduan Pasar Ikan Laut Segar di Pasar Muara Baru Jakarta Utara dan Pasar Jembatan Lima Jakarta Barat dapat disimpulkan sebagai berikut :

1) Berdasarkan Index Of Market Connection dari keempat ikan yang digunakan dalam penelitian ini yaitu Bandeng, Kembung, Tenggiri, dan Tongkol didapatkan bahwa terdapat keterpaduan pasar jangka pendek dan jangka panjang di tiga ikan yaitu Bandeng, Kembung, dan Tenggiri. Sedangkan untuk ikan Tongkol hanya terdapat keterpaduan jangka pendek dan tidak terdapat keterpaduan jangka panjang.

2) Kondisi pasar ikan di Muara Baru dan Jembatan Lima cukup strategis dan para pelapak ikan pun tertata dengan rapih sehingga terciptanya kenyamanan saat proses transaksi jual beli antar pedagang dengan konsumen.

\section{Saran}

1) Perlu adanya penelitian lebih lanjut mengenai keterpaduan pasar ikan laut segar. Dengan adanya penelitian lebih lanjut diharapkan bisa untuk lebih mengoptimalkan 
informasi mengenai keterpaduan pasar khususnya keterpaduan pasar ikan laut segar di Jakarta.

2) Kondisi pasar yang rapih di Muara Baru dan Jembatan Lima harus tetap dipertahankan atau bahkan ditingkatkan kembali agar para pengunjung bisa lebih nyaman dalam melakukan proses transaksi jual beli di pasar tersebut.

\section{Daftar Pustaka}

Agatha Wahyu Widati, Dwidjono Hadi Darwanto, Masyhuri. 2011. Analisis keterpaduan pasar beras di kabupaten manokwari. Pascasarjana Ekonomi Pertanian, Fakltas Pertanian Universitas Gadjah Mada. Agro Ekonomi Vol. 18 No. 1 Juni 2011, hal. 51-60.

Clenia, M. 2009. Optimalisasi Informasi Pasar Ikan Tongkol (Auxis Thazard) Antara Pekalongan Dengan Jakarta, Jurnal Bisnis dan Ekonomi (JBE), September 2009, Hal. 140 - 148 Vol. 16, No.2 ISSN: 1412-3126.

Fauziyah, 2011. Integrasi Pasar Ikan Tongkol di PPN Pekalongan dan PPS Nizam Zachman Jakarta, Maspari Journal 03 (2011) 15-19.

Koeshandoko, H. 2006. Kajian Sistem Pemasaran dan Keterpaduan Pasar Ikan Laut Segar di Pangkalan Pendaratan Ikan Bajomulya, Juwana Kabupaten Pati, Jawa Timur. Tesis. Program Magister Agribisnis. Institut Pertanian Bogor.

Sitorus, E. 2004. Keterpaduan Pasar Tuna Segar Benoa/Bali, Indonesia Dan Pasar Angkatan - 3. Sentral Tuna Tokyo, Jepang. Tesis. Program Magister Agribisnis. Universitas Uday 